\title{
El origen del libro de texto gratuito en México: entre la gratuidad educativa y los desafíos del mundo editorial en los cincuenta
}

\author{
The Origin of the Free Textbook \\ in Mexico: Between Free Education \\ and the Challenges of the Editorial World \\ in the 1950s

\section{Elizer Ixba Alejos} \\ Universidad Autónoma de la Ciudad de México \\ elizer.ixba@uacm.edu.mx
}

\begin{abstract}
Resumen
Las explicaciones sobre el origen del libro de texto gratuito (LTG) en México se han centrado en la gratuidad educativa y en las disputas por el control de la educación. Esta perspectiva, que asume vínculos entre el Plan de Once Años y este tipo de libro, le presta escasa atención como material impreso y a sus conexiones con el mundo editorial. A contracorriente, apoyada en la historia de libros escolares y en un diálogo con diversas fuentes, argumento que el origen del LTC, aunque revestido de política educativa para posibilitar la gratuidad, también se corresponde con problemas de la producción editorial mexicana en los años cincuenta. Asimismo, a la luz de iniciativas y debates sobre la lectura que tuvieron lugar en esos años, especulo que el LTC no únicamente pretendía llenar un vacío educativo, sino también contrarrestar prácticas de lecturas de otro tipo, como las historietas, consideradas "perniciosas" por algunos grupos sociales
\end{abstract}

Palabras clave: libro de texto gratuito, historia del libro, textos escolares, Plan de Once Años, México.

\section{Abstract}

Explanations about the origin of the so-called Free Textbook in Mexico have focused on the government interest in providing free education and on the disputes over the control of education by various actors. Those explanations, which tend to assume that there was a direct link between the Plan de Once Años and the Free Textbook, pay little attention to the character of textbooks as 
printed objects and their connections with the editorial world. By contrast, from a perspective derived from the history of school textbooks, and in dialogue with a number of different sources, I argue that the origin of the Free Textbook, although part of an educational policy aimed at making free education possible, was also a response to problems and limitations of the Mexican publishing industry in the 1950s. Likewise, in the light of initiatives and debates about reading practices that took place in that decade, I speculate that the Free Textbook did not only intend to fill in an educational void, but also to counteract the reading of other materials such as comics, which were considered "pernicious" by some social groups.

Keywords: Free Textbook, history of the book, school textbooks, Mexico.

En los albores del gobierno de Adolfo López Mateos, frente a un desafiante panorama educativo, se formalizaron y pusieron en marcha dos proyectos de reconocida trascendencia para la educación en México: el Plan para el Mejoramiento y la Expansión de la Educación Primaria (Plan de Once Años) y el Libro de Texto Gratuito (LTC). En la versión oficial, el origen de ambas iniciativas responde al mandato de proporcionar educación primaria gratuita y obligatoria para los niños mexicanos. Esta idea, en el caso del Plan de Once Años, se refuerza al enfocarse en su proceso de diseño, propósitos y líneas de acción de las que ha dado cuenta su artífice: Jaime Torres Bodet.

No ocurre lo mismo con el Libro de Texto Gratuito. Al poner en perspectiva su fecha de formalización, la manera en la que se puso en marcha, su relación con el Plan de Once Años, el contexto editorial de su tiempo y la participación de Martín Luis Guzmán, la explicación de su origen centrada sólo en la gratuidad educativa se agrieta y se torna insuficiente. ¿Por qué el Plan de Once Años y el LTG, a pesar de coincidir en propósitos, inician y se formalizan por separado? ¿Por qué el primero, como estrategia de planeación educativa encaminada al logro de la gratuidad y obligatoriedad educativa, no incluyó de manera explícita al segundo? ¿Por qué en uno se involucró más el secretario de Educación y el otro se encargó a un editor y escritor? ¿Por qué Martín Luis Guzmán, conocedor del tejido editorial mexicano y empresario de este sector, promovió y llevó a buen puerto un proyecto que parecía contrario a sus intereses editoriales y a los de su gremio?

En este artículo, a partir de algunos discursos acerca del libro y de la lectura en el México de los cincuenta, asumo que la creación del LTC, aunque vinculada con la gratuidad educativa, también responde a dificultades que enfrentaba el mundo editorial y de la lectura en México en los años cincuenta: mercado con ingente presencia de libros de ascendencia española (de texto, literatura y de consulta), obstáculos en la exportación, limitaciones técnicas y materiales, libros caros e insuficientes, distribución concentrada en la capital del país, escasa 
producción y difusión de obras de autores mexicanos, así como la existencia de un sector del mercado de lectores seducido por lecturas inconvenientes: las historietas.

El contenido de la exposición se organiza en tres apartados: en el primero se aborda el distanciamiento entre el Plan de Once Años y el LTC; el segundo proporciona un panorama sucinto de la complejidad y desafíos del libro mexicano en los años cincuenta; mientras que en el tercero se presenta la práctica de la lectura de historietas como uno de los retos en el mercado de libros. Finalmente, se plantean algunas reflexiones para continuar el debate sobre el origen del LTC.

\section{El Plan de Once Años y el LTC: desencuentros}

En general, los investigadores de la obra educativa en el periodo de Adolfo López Mateos establecen vínculos estrechos entre el Plan de Once Años y el LTG (Meneses, 1988; Greaves, 1999; Villa, 2009; Schmelkes, 2010; Loyo, 2011). Para Schmelkes, la verdadera gratuidad pretendida en el plan impulsado por Torres Bodet requería de los libros de texto gratuitos. Aurora Loyo resalta que "una mayor atención a las normales, la inmediata ampliación del número de plazas para maestros y la mejoría del sueldo magisterial", indicadas en el plan, serían insuficientes si "no se conseguía dotar a todos los niños de los LTC" (Loyo, 2011: 138). En el mismo sentido, Lorenza Villa Lever (2009: 45) considera que abrir escuelas e invertir en la formación de los maestros no bastaría para hacer realidad la gratuidad educativa si el Estado no invertía en compensar diferencias socioeconómicas que produjeran un mejor reparto del saber. Los vínculos señalados tienen su fundamento en dos premisas:

1) La del LTC como iniciativa forjada en la necesidad de impulsar la gratuidad de la educación en México, que se alcanzaría al separar "la edición de libros de texto de cualquier interés lucrativo" (Villa, 2009: 47).

2) El Plan de Once años como estrategia de planeación que proporcionó unidad, coherencia y sentido a la obra educativa lopezmateista y que tuvo como propósito "garantizar a todos los niños de México la educación primaria gratuita y obligatoria" (Schmelkes, 2010; Torres, 2005: 249).

Ambas propuestas, aunque en lo oficial coinciden en el propósito de la gratuidad educativa, difieren en su origen, fecha de formalización y desarrollo. El 30 de diciembre de 1958, a casi un mes de haber rendido protesta como presidente de México, Adolfo López Mateos formalizó, a instancias de Jaime Torres Bodet (2005a), la creación de una comisión encargada de "estudiar un plan nacional para resolver el grave problema" que representaba el hecho de 
que un gran número de niños en edad escolar no pudiera "recibir la enseñanza gratuita y obligatoria" (DOF, 1958). La comisión dispondría de casi ocho meses (del 9 de febrero al 30 de septiembre de 1959) para elaborar un plan sustentado en el tamaño de la demanda educativa real y en los requerimientos legislativos, presupuestales y de convenios entre los tres niveles de gobierno. En octubre de 1959, Jaime Torres Bodet presentaría el plan a López Mateos para que expidiera los decretos y acuerdos procedentes, y presentara al Congreso de la Unión las iniciativas del caso (DOF, 1958).

Jaime Torres Bodet y la comisión, apegados al proceso indicado en el decreto, trabajaron arduamente en elaborados muestreos y análisis de estadísticas educativas y poblacionales, estimaron recursos económicos necesarios, identificaron fuentes de financiamiento y definieron líneas de acción (Torres, 2000; Meneses, 1988; Secretaría de Industria y Comercio, 1961). En este trabajo de meses se diseñó el Plan Nacional para la Expansión y el Mejoramiento de la Enseñanza Primaria en México.

El Plan, presentado por López Mateos el $1^{0}$ de diciembre de 1959, consideraba: la construcción y mejora de aulas, aumento de plazas docentes, ampliación de los servicios del Instituto Federal de Capacitación del Magisterio, fortalecimiento de escuelas normales e instalación de centros regionales de enseñanza normal y nuevos programas de educación primaria (Torres, 2005a; Torres, 2000; Meneses, 1988). Sobre el libro de texto gratuito nada se mencionó.

El 12 de febrero de 1959, a dos días de iniciados los trabajos de la comisión para elaborar el Plan de Once Años, Adolfo López Mateos expidió un nuevo decreto. Esta vez para ordenar que se creara la Comisión Nacional de Libros de Texto Gratuitos (Conaliteg). Su encomienda: fijar las características de los libros de texto destinados a la educación primaria, encargarse de su edición y cuidar que estos materiales tendieran "a desarrollar armónicamente las facultades de los educandos", prepararlos para la vida práctica e inculcaran en ellos la solidaridad, virtudes cívicas y el amor a la patria. En este decreto ninguna referencia se hizo al Plan Nacional para la Expansión y el Mejoramiento de la Enseñanza Primaria.

Así, mientras Jaime Torres Bodet y otros trabajaban arduamente en la conformación de un plan para expandir y mejorar los servicios educativos, Martín Luis Guzmán, designado como presidente de la Conaliteg, se encargaba de hacer posible que a principios de 1960 se contara con textos escolares en tirajes nunca antes realizados en México. En todo este tiempo, "se le dieron poderes totales para elaborar los libros. Controlaba el proceso de creación y aprobación de originales, la ilustración, el diseño gráfico, la producción física de los libros y su distribución por todo el país" (Díaz, 2006: 58; Ixba, 2014).

Ambas iniciativas, a pesar de compartir el propósito de avanzar en la gratuidad y obligatoriedad educativa, corrieron por vías separadas y diferentes. Las metas y líneas de acción del Plan de Once Años se forjaron en el acopio y análisis de cifras para conocer el problema educativo 
que se enfrentaba; y en la estimación de recursos y necesidades de convenios. Todo este trabajo permite afirmar que el plan en cuestión se fraguó en el gobierno de Adolfo López Mateos, al inicio de su mandato. En cambio, el LTG, con las debidas proporciones respecto del Plan de Once Años, fue un proyecto que se aprobó y se puso en marcha, en apariencia, sin un trabajo previo que diera cuenta del estado del libro escolar y de las lecturas en las escuelas del país. Es posible que tal diagnóstico fuera innecesario en virtud de tres razones: 1) Los amplios conocimientos que Martín Luis Guzmán tenía sobre la industria editorial mexicana; 2) la falta de libros de textos y de lecturas en el país era un problema muy conocido y añejo, y 3) la creación de la Conaliteg era parte de un proyecto forjado desde tiempo atrás y que sólo había esperado el momento propicio para llevarse a cabo.

En cualquier caso, lo que resalta es la distancia entre el origen y puesta en marcha del Plan de Once Años respecto del LTC, incluso en el plano curricular. Los nuevos planes y programas de 1960, elaborados como parte de las acciones del Plan, se organizaban por necesidades y propósitos, mientras los primeros libros de texto gratuitos, que se correspondían con los programas de 1957, respondían a una organización por materias y temas de enseñanza (Villa, 2009: 87).

Este desfase, y los anteriores, no son asuntos menores frente al importante esfuerzo que se estaba realizando para planificar la educación, para emprender acciones articuladas y desde el conocimiento de la problemática educativa. Se trata, más bien, de indicios que evidencian al LTG como un proyecto que no embona fácilmente en la lógica del origen, diseño y operación del Plan de Once Años. Si esto es así, ¿cuál sería la lógica en la que embonaría mejor?, ¿qué sugeriría esto en cuanto a su origen? La faceta del LTC como material impreso ofrece pistas al respecto.

\section{El mundo editorial mexicano en los cincuenta}

En 1960 se elaboraron y distribuyeron en primarias del país alrededor de 15.5 millones de libros de texto gratuitos (Conaliteg, 1994: 89 y 163). ${ }^{1}$ Una cifra inédita en México, en su historia del libro y en la historia de libros escolares. ${ }^{2}$ Éstos fueron los primeros libros para muchos niños y hogares mexicanos. De acuerdo con Martín Luis Guzmán, por primera vez en la historia de la educación en México, a los niños se les repartió "uniforme e igualitariamente

${ }^{1}$ IISUE-Fondo MLG, caja 239.

2 Es probable que se piense en el programa editorial de José Vasconcelos y en los tirajes de cartillas para la alfabetización. Sin embargo, en el caso de Vasconcelos, la conformación de bibliotecas públicas, escolares, obreras y ambulantes incluyó la compra de libros, más que su producción. Las cartillas, estiman algunos, alcanzaron tirajes de diez millones de ejemplares. 
los medios y el hábito de leer" (Hernández, 1986: 162). La afirmación del escritor no carece de fundamentos.

La lectura y los libros, escolares y en general, nunca han sido, ni son, un bien al alcance de todos los mexicanos. Valentina Torres Septién (1999: 322) estima que, a finales de los cuarenta, "existía en el país una librería por cada 132,000 habitantes" y que de las 159 registradas, 89 se localizaban en el Distrito Federal y 70 en los estados de la república. La tendencia no cambiaría en la década siguiente, la oferta de libros, además de cara, seguía siendo insuficiente y beneficiando, como hasta ahora, a los capitalinos. Las editoriales y librerías se concentraban en la Ciudad de México, a pesar de que sólo albergaba al 11 por ciento de la población del país. Los libros, tanto nacionales como importados, no llegaban a la gran mayoría de los alfabetizados dispersos a lo largo y ancho del territorio mexicano.

De los libros que se producían en México, se calcula que el 25 por ciento se destinaba al consumo nacional y el 75 por ciento se exportaba a países de habla española como Argentina, Colombia, Costa Rica y Cuba. Entre 1957 y 1960, treinta y cuatro empresas editoriales publicaron 4,332 obras. Una oferta reducida, incluso para el mercado de lectores de la capital del país (Torres, 1999: 300). La producción nacional de libros estaba sujeta, y por lo mismo limitada, a subsidios y condonaciones de derechos aduanales. Experimentaba, además, dificultades en el abasto de papel, cartón, telas para la encuadernación, tintas y pegamentos. ${ }^{3}$

El mercado de libros de texto también era insuficiente. En 1959, los tirajes, de acuerdo con registros del secretario general de la Conaliteg, Juan Hernández Luna, no se correspondían con el número de niños inscritos en las escuelas primarias. Para una población de dos millones que cursaban el primer grado, la oferta de la iniciativa privada era de apenas 240,000 libros para la asignatura de lectura (Hernández, 1975, citado por Villa, 2009: 39). Como en el caso de los libros en general, la oferta de textos escolares se restringía a la capital del país y ciudades principales.

En los años cincuenta, el alto costo de los libros era también un obstáculo para que muchos mexicanos accedieran a éstos. En 1955, un trabajador, percibiendo el salario mínimo entre 7 y 8 pesos, mientras que el costo de los libros escolares oscilaba entre 3 y 8 pesos. Una enciclopedia podía alcanzar un valor de 13 pesos. Desde luego, también había ofertas. Con cien pesos podía comprarse un paquete de cien libros con un valor original de 576 pesos (Letras..., 1955). El encarecimiento de los libros se debía a varias razones: aplicación de aumentos indebidos por parte de libreros y editoriales, devaluación del peso y sus efectos en el costo del papel, desmedida especulación de importadores de libros y fallas en la regulación de precios por parte del gobierno mexicano (Ixba, 2013).

${ }^{3}$ IISUE-Fondo MLG, caja 220, expediente 4. 
Los libros eran caros. Por su valor se utilizaron como objeto de transacciones en las casas de empeño. Era tal el número de libros empeñados en los montepíos, que en 1955 estudiantes universitarios solicitaron al presidente Ruiz Cortines que no salieran a remate público y que se entregaran a alumnos de escasos recursos previo pago de la cantidad en la que habían sido empeñados, más los gastos del Montepío (Excélsior, 1955).

Desde principios de los cincuenta, la carestía de los libros era un tema que preocupaba a empresarios, estudiantes y profesores. El 16 de julio de 1953, Martín Luis Guzmán envió al secretario de Educación Pública, José Ángel Ceniceros, un proyecto relacionado con el comercio de libros de texto, el cual consistía en crear "una comisión, dotada por la Presidencia de la República con todas las facultades y la autoridad", para reglamentar el comercio de libros de texto en el territorio nacional, así como para adquirir directamente de autores-editores, mexicanos y extranjeros, libros escolares para alumnos de educación superior del país; que se venderían a precio de costo y sin intermediarios (en casi 50 por ciento menos de su valor en librerías), y lo mejor, aseguraba Guzmán, no se lastimaría "el legítimo derecho de ninguno" 4

En 1954, como reacción gubernamental al alto costo de los libros de texto, se creó la Comisión Nacional Proabaratamiento del Libro y se recomendó que los textos no se utilizaran como cuadernos de trabajo para alargar su utilidad. Los intentos de la SEP por regular y abaratar los precios de los libros escolares no fructificaron, las editoriales y los libreros no siempre tomaban en cuenta los precios fijados por la SEP (Ávila y Muñoz, 1999).

La industria editorial mexicana, además, mostraba una fuerte presencia de España, una escasa producción de autoría nacional, así como problemas de difusión y para exportar. En abril de 1953, la Federación Estudiantil Universitaria (FEU)5 advertía que en México existía un monopolio de libros en manos de extranjeros. ${ }^{6}$ El general Rubén García, presidente del Comité Nacional de Restauradores de la Mexicanidad, estaba convencido de que los responsables eran "los gachupines", españoles que, en su juicio, también ejercían control sobre los asuntos culturales y de la alimentación en México. ${ }^{8}$

El monopolio, explicaba la FEU, provocaba que "la clase proletaria y los estudiantes cayeran en las garras de los explotadores del vicio", pues la falta de libros cerraba las puertas a la educación, al perfeccionamiento de los alumnos de todas las escuelas y a la distracción

${ }^{4}$ IISUE-Fondo MLG, caja 220, expediente 7.

${ }^{5}$ En 1953 el comité de la FEU estaba integrado por Pablo Camarena O’Farril (presidente), Juan José Castillo Mota (vicepresidente), Rafael Lara Navarro (secretario general), Miguel de la Madrid Hurtado (subsecretario general), Héctor Hernández (oficial mayor), Jorge Rivera Rosales (tesorero) y Carlos Quesnel Arronis (secretario de actas). La FEU asumía la representación colectiva de la UNAM.

${ }^{6}$ AGN, Fondo Adolfo Ruiz Cortines, caja 0879, expediente 521.8/195.

${ }^{7}$ Al parecer, el general Rubén García (1896-1974), oriundo de Puebla, participó en el ejército constitucionalista, y fue agregado militar en Chile, Bolivia, Francia, España e Italia; subjefe de la Comisión de Historia de la Secretaría de Guerra y Marina. Perteneció a asociaciones como la Academia Nacional de Ciencias y Artes "Antonio Alzate".

${ }^{8}$ AGN, Fondo Adolfo Ruiz Cortines, caja 0866, expediente 437.1/327. 
sana. ${ }^{9}$ Por ello, en una manifestación del 5 de junio, la FEU solicitó al presidente de México que interviniera para desaparecer los monopolios y que la Secretaría de Educación Pública se encargara de la importación de libros escolares, con el fin de venderlos a precios moderados y dar facilidades de pago a los estudiantes. ${ }^{10}$

La presencia española en el tejido editorial mexicano de principios de los cincuenta era notoria. Por un lado, estaba la impronta de editores exiliados como José González Porto y Rafael Ciménez Siles ${ }^{11}$ y, por el otro, la importación de libros de ese país. Para María Fernández Moya (2009: 23, citado por Ixba, 2013), durante el siglo xx, la industria editorial española experimentó un proceso de internacionalización largo, rentable y exitoso: "Un proceso que tuvo su origen, y su principal cliente, en los países latinoamericanos".

El intercambio comercial de libros entre México y España era desigual. El primero enfrentaba tres problemas en sus exportaciones al segundo. Uno de ellos consistía en la detención, deliberada o no, de sus envíos en oficinas de aduanas y servicio postal de España. En octubre de 1956, treinta y dos paquetes de libros fueron intervenidos por la Oficina de Cambio de la Administración Principal de Aduanas de la Provincia de Santander. ${ }^{12}$ Algo similar, pero en el correo de Madrid, ocurrió en abril de 1958. El segundo problema se refiere a los tropiezos del libro mexicano derivados de los aranceles españoles. Gravámenes elevados y difíciles de calcular, debido a las bases establecidas y a las múltiples características de los libros:

\begin{abstract}
Una obra que lleve intercalada una buena proporción de grabados o mapas, puede verse afectada por la aplicación de la Partida No. 1074 [...], que se refiere a los grabados impresos en un solo color, y de la cual establece un gravamen de 3.26 pesetas oro por kilogramo; o bien puede verse afectada por la Partida No. 1075 [...], relativa a los grabados impresos en varias tintas, partida que establece el gravamen de 3.62 pesetas oro por kilogramo de peso; y así mismo toda clase de mapas quedan afectado por la Partida No. $1081 .^{13}$
\end{abstract}

En contraste, el libro español a su entrada en México liquidaba un solo gravamen y siempre inferior a la mitad de la suma de los diversos impuestos que pagaba el libro mexicano en España. El tercer problema, de acuerdo con empresarios editoriales, se refería al régimen de censura

\footnotetext{
${ }^{9}$ AGN, Fondo Adolfo Ruiz Cortines, caja 0879, expediente 521.8/195

${ }^{10} / \mathrm{dem}$

${ }^{11}$ José González Porto, Joan Grijalbo y Rafael Giménez Siles son considerados como tres figuras fundamentales del exilio en el mundo del libro: Leyenda, Editorial Séneca, Edición y Distribución Iberoamericana de Publicaciones, S.A. (Ediapsa), Grijalbo, Joaquín Mortiz y Ediciones Atlántida fueron algunos sellos creados por los "transterrados".

12 IISUE-Fondo MLG, caja 220, expediente 4.

${ }^{13} / \mathrm{dem}$.
} 
previa española: exigía entregar tres ejemplares de cada título que se deseara exportar y rechazaba un buen número de impresos mexicanos, incluso del Fondo de Cultura Económica. ${ }^{14}$

La difusión del libro mexicano y extranjero también era dispar. Para Ramiro Aguirre, jefe de redacción de El Libro y el Pueblo, las obras nacionales, especialmente las novelas, enfrentaban el poco aprecio de editores y libreros. "Podrían recorrerse las librerías de la Ciudad de México, y las de todos los estados y se constataría, de manera evidente, la carencia, quizás absoluta, de libros de autores mexicanos" (Letras..., 1956: 1). Esto se debía, explica Gilberto Basa, director de la revista Letras..., a la escasa rentabilidad de estas obras, en virtud de su falta de lectores, así como a lo benéfico de "lanzar al mercado libros conocidos mundialmente y sin pagar derechos de autor, que obras de escritores mexicanos pagando derechos de autor y los que muchas veces son desconocidos aun dentro del territorio nacional" (Letras..., 1956: 1).

El mercado de libros de texto de los años cincuenta también revela indicios de la tensión entre nacionales y extranjeros. En 1959, de acuerdo con Ana Cristina Ávila y Virgilio Muñoz (1999), de las treinta y seis editoriales que publicaban libros de texto, varias pertenecían a españoles radicados en México y tenían presencia significativa en las listas de obras autorizadas por la SEP. Es el caso de Patria, Herrero Hermanos y Luis Fernández G. Herrero Hermanos era una empresa de españoles, ${ }^{15}$ principalmente dedicada a publicar libros de texto de profesores mexicanos, como Daniel Delgadillo. La SEP mantuvo la autorización de títulos de este autor hasta después de 1960.

Como he documentado en otro artículo, a principios de los cincuenta, en las listas oficiales era notoria "la presencia del exiliado Santiago Hernández Ruiz como el autor con mayor número de títulos autorizados y Luis Fernández G. como el sello que los publicaba" (Ixba, 2013). En 1952, Hernández Ruiz contaba con doce obras autorizadas por la SEP: diez libros de texto ${ }^{16}$ y dos de consulta. ${ }^{17}$ Esto lo colocaba por encima de autores mexicanos como Rosaura Lechuga, ${ }^{18}$ Daniel Delgadillo, Alfredo y Carmen G. Basurto, quienes en promedio

${ }^{14}$ Idem

${ }^{15}$ Leoncio y Guillermo Herrero fundaron en 1890 la librería religiosa Herrero Hermanos, origen del sello editorial homónimo (Zahar, 2000: 101).

${ }^{16}$ Publicados por Luis Fernández G.: Amanecer, libro de lectura para primer año; Primeras luces, libro de lectura para segundo año; Nosotros, libro de lectura para tercer año; Curiosidades y ejemplos, libro de lectura para cuarto año; Continente, libro de lectura para quinto año; Cultura y espiritu, libro de lectura para sexto año. Bajo el sello de Herrero Hermanos: Aritmética y nociones de geometría, para primero, segundo y tercer ciclos; Historia de América, para quinto grado.

${ }^{17}$ La escuela en acción, primer y segundo semestres.

${ }^{18}$ Formó parte de la mesa directiva de los congresos de educación socialista, al lado de Juan Guerrero, Ismael Rodríguez y Vicente Rivera. En 1941, su libro Camaradas (Editorial Patria), primer y segundo años, se encontraba en la lista oficial de la SEP. Durante el gobierno de Miguel Alemán continuaba en el catálogo oficial; no obstante, fue uno de los libros de texto que más se criticaron en la prensa, muy posiblemente por su tendencia socialista. En 1945, participó en la Conferencia Pedagógica del Sindicato Nacional de Trabajadores de la Educación, como primera secretaria de la mesa directiva (Meneses, 1988). 
contaban, en el catálogo de ese año, con cinco textos aprobados por la Comisión Revisora de la SEP.

Esta tendencia no habría de pasar inadvertida. En 1956, el profesor Salvador Hermoso Nájera ${ }^{19}$ señaló: "En la lista oficial se favorece ostensiblemente a la editorial Herrero Hermanos, S.A., y se elimina de la competencia a muchas editoriales mexicanas pequeñas y a otras que no tienen apoyo oficial". ${ }^{20}$ El cuestionamiento puede interpretarse como una defensa de intereses que veían amenazados por algunas editoriales y por la propia Comisión Revisora de Libros de Texto y de Consulta. Las primeras habían encontrado mecanismos para subvertir los procesos de dictaminación; mientras que la segunda eliminaba títulos bajo criterios que favorecían a algunos, en detrimento de otros.

Salvador Hermoso Nájera acusaba a la Comisión Revisora de funcionar irregularmente y como un "Tribunal de la Santa Inquisición", pues en 1956 había retirado de la lista 187 libros de texto para incluir títulos eliminados en listas anteriores. Era el caso de obras de Daniel Delgadillo publicadas por Herrero Hermanos. El profesor Nájera afirmaba que estaba dispuesto a mostrar en un debate público que la geografía de Delgadillo era deficiente respecto de las obras que había desplazado la SEP, así como a dar evidencias de las irregularidades con las que ésta operaba en la autorización de los libros de texto. La opacidad de las autoridades educativas en el proceso de revisión de impresos escolares salía a relucir.

En este panorama de tensiones editoriales, no era extraño encontrar recomendaciones como éstas:

México necesita muchos libros de autores extranjeros; pero, de manera incuestionable, necesita, sobre todo, una formidable producción de libros ciento por ciento mexicanos, es decir, libros planeados, escritos, editados y distribuidos para elevar la cultura del lector mexicano y del mismo pueblo analfabeto, para enseñarle el ABC del idioma [...]. Se habla, en general, de todos los libros editados en México y, en particular, de los escritos por autores mexicanos (Letras..., 1959: 3).

La tensión nacional-extranjero no se restringía al mundo editorial. En 1953, el grupo Preparatorianos 1920-192421 difundió el Ideario de la mexicanidad, un texto en el que llamaban a defender y preferir lo nacional (Índice..., 1953).

19 Salvador Hermoso Nájera fue inspector federal escolar (1940), miembro del Departamento Técnico de la Dirección General de Educación Primaria en los Estados y Territorios, profesor en el Instituto Federal de Capacitación del Magisterio, autor de obras pedagógicas y libros de texto relacionados con la enseñanza de la geografía. En 1948 participó activamente en el Primer Congreso de Educación Rural, en el que se discutieron temas como la construcción de escuelas rurales en el país, así como tareas y desafíos de la educación rural frente a la industrialización y transformación agrícola en México (Gallo y Gómez, 1948).

${ }^{20}$ AGN, Fondo Adolfo Ruiz Cortines, caja 0866, expediente 545.2/94.

${ }^{21}$ Miguel Alemán Valdés, presidente de México en el periodo 1946-1952, fue el fundador de este grupo. 
En este escenario y sus demandas, la creación del LTC adquiere tonos nacionalistas de protección e incentivo a la industria editorial mexicana. Incluso, como se indica en un estudio pionero sobre esta iniciativa, "la Comisión Nacional de Libros de Texto Gratuito abría una nueva etapa en la historia del nacionalismo mexicano" (Vázquez, 2000: 278). Los contenidos de los primeros textos gratuitos, en correspondencia con el espíritu de estos años, fueron una exaltación de la unidad nacional y la mexicanidad. Josefina Zoraida Vázquez (2000), Eduardo Weiss (1982), Lilian Álvarez de Testa (1999), Dalila Chine (2007), entre otros, han hecho aportes en este sentido.

\title{
Disputas por los lectores
}

De acuerdo con los testimonios anteriores, la industria editorial mexicana, específicamente la de autoría nacional, tenía pocos lectores en el país. Ello se explicaría por la falta de difusión de estas obras, la competencia con el libro español, la concentración de su oferta en la Ciudad de México, así como por la intensa lectura de historietas.

En 1954, Emmanuel Carballo escribió: "la resolución del problema fundamental de nuestra literatura, la carencia de lectores, no la resuelve la abundancia de obras auspiciadas por el Estado. Más que dar becas, hay que dar letras" (El Libro y el Pueblo, abril de 1954: 40). La falta de lectores alcanzaba al Parnaso mexicano de letras:

\begin{abstract}
Los últimos años de don Alfonso ${ }^{22}$ son a un tiempo de triunfo y de fracaso. De éxitos porque los mexicanos esclarecidos dictaminaron que su obra era parte del patrimonio nacional. De infortunio porque los lectores brillaron por su ausencia. Unas cuantas decenas de textos magníficos, de diversa índole, no tuvieron los destinatarios para los cuales fueron escritos (Carballo, 2004: 195).
\end{abstract}

Sin embargo, en México sí se leía, y en apariencia bastante, aunque un género de literatura cuestionable para los promotores de la cultura del libro. Para algunos escritores nacionales, los lectores de la novela mexicana, y otros libros, eran escasos, debido a que enfrentaban a un "gravísimo enemigo" a mediados de los cincuenta: las revistas de "monos" (El Libro y el Pueblo, abril de 1954).

En México, las historietas ocupan un lugar significativo en las prácticas de lectura, incluso han funcionado como incentivo alfabetizador y cimiento de empresas editoriales con ganan-

22 Alfonso Reyes (1889-1959) era considerado por Emmanuel Carballo como "de los pocos milagros que se han dado en territorio mexicano en el siglo Xx. Tenía el don de la palabra. Es el hombre que supo darle al lenguaje un nicho específico que antes no había sido dado por nadie. La forma de su decir no tiene paralelo en la literatura mexicana y en la latinoamericana" (Carballo, 2009). 
cias millonarias. Las campañas de alfabetización emprendidas desde principios de los años veinte y los esfuerzos educativos oficiales contribuyeron a la conformación de un público lector que, en la década de los cuarenta y posteriores, se entregó con avidez a la lectura de historietas, convirtiendo esta práctica en "un fenómeno cultural de masas" (Aurrecoechea y Bartra, 1993: 15).

En México, la historieta es un género que abarca un conjunto amplio y diverso de revistas ilustradas. Los contenidos de estas publicaciones incluyen temas relativos al amor romántico, indios, vaqueros, historietas estadounidenses (como Bugs Bunny), personajes populares y sexo. Su público lector, entre los cuarenta y cincuenta, se ubica en el territorio de la familia. La intensa lectura de historietas, explican algunos, se debe a su popularidad, facilidad para leerlas y su narrativa en episodios con final feliz (Aurrecoechea y Bartra, 1993; Rubenstein, 2004). En la década de los cincuenta, algunas de las revistas más leídas eran Pepín, Chamaco, Memín Pinguín, El Ilanero solitario, La familia Burrón, Lágrimas, risas y amor. Para los adultos que preferían fotos de Tongolele, Su Muy Key o Kalantán, se publicaba Vea y Vodevil.

Las historietas, en opinión de sus críticos, eran lecturas de contenido inmoral y contrarias a los afanes nacionales de modernidad. Su género, popular y sin mayores exigencias de competencias lectoras y recursos narrativos, ponían en peligro los propósitos de la educación pública al difundir modelos de conducta inapropiados y conocimientos distintos de los que se debían adquirir en los centros escolares. En esta lógica, se demandaba la intervención del Estado para salvaguardar la educación de los mexicanos.

El 19 de marzo de 1955, el periódico Últimas Noticias publicó una nota para informar que la Federación de Estudiantes Universitarios (FEU), que en 1953 se había pronunciado en contra del monopolio del libro, organizaría una quema de historietas. La razón, argüían los jóvenes, es que por su contenido se trataba de "un veneno activo" para la mentalidad de los niños mexicanos. Siete días más tarde, la anunciada quema se llevó a cabo. "Decenas de estudiantes universitarios se concentraron en la Plaza de Santo Domingo", con el fin de llegar a la explanada central de la capital; "llevaban cartelones en los que se pedían libros baratos y se exigía la suspensión de la publicación de revistas pornográficas". Algunos más coreaban su petición de cárcel para los "envenenadores de la juventud" (Pérez, 2011: 83-84).

La lectura de historietas venía de tiempo atrás, igual que las críticas e intentos por atajarla. El 15 de marzo de 1951, Miguel Alemán expidió el "Reglamento de los artículos 4 y 6, fracción VII, de la Ley Orgánica de la Educación Pública, sobre publicaciones ilustradas en lo tocante a la cultura y a la educación", con la finalidad de determinar lo que era inmoral y contrario a la educación y a la cultura mexicanas (DOF, 1951). Antes, en 1944, Manuel Ávila había firmado un documento similar: el "Reglamento de revistas ilustradas en lo tocante a la educación" (DOF, 1944). 
Para los hombres de letras, así como para profesores y religiosos, las historietas eran "enemigos gravísimos" de la literatura, el idioma y la decencia. Su lectura hundía al pueblo en la incultura y embotaba la mente. "Por desgracia nuestra y para completar el infortunio, las autoridades han cerrado ojos y oídos a este problema de proporciones fabulosas, que tarde o temprano dará los resultados a que ha sido encaminado: embrutecimiento general (El Libro y el Pueblo, abril de 1954).

Del lado magisterial, el 11 de febrero de 1956, tres años antes de crearse el libro de texto gratuito, el profesor Salvador Hermoso Nájera escribió una carta abierta dirigida al profesor Enrique M. Sánchez, secretario general del Sindicato Nacional de Trabajadores de la Educación, en la que acusaba que "mientras la niñez mexicana estaba siendo absorbida por la lectura de pasquines, nacionales y extranjeros", se eliminaba del catálogo oficial de libros de texto lecturas de reconocidos autores. ${ }^{23}$ ¿Será más perjudicial la lectura de esos autores o la de los pasquines para los niños?, preguntaba Hermoso Nájera a la SEP. ${ }^{24}$

Ese mismo año, el profesor Herculano Ángel Torres Montalvo dirigió una encuesta entre alumnos de 12 a 18 años, inscritos en secundarias del Distrito Federal, con el fin de conocer sus tendencias literarias. Los datos mostraron que el 83 por ciento de esa población leía con frecuencia revistas ilustradas; 15 por ciento raras veces las leía, y 2 por ciento declaraba no haber leído nunca este tipo de revistas. De una lista de 105 títulos, las favoritas eran El conejo de la suerte, Cuentos de Walt Disney, La pequeña Lulú, Tarzán, El super ratón, El Ilanero solitario y La familia Burrón, entre otros títulos. Estas publicaciones, aunque no se tacharon de inmorales, se valoraron como materiales faltos de calidad en su contenido y formato, y con propósitos ajenos a los de la educación secundaria (Torres, 1956).

Las conclusiones difundidas en la Revista del Instituto Nacional de Pedagogía insistían en que "el Estado mexicano y algunas instituciones particulares" debían prestar ayuda económica y estimular a editoriales dispuestas a publicar libros y revistas con un contenido eminentemente educativo. Asimismo, advertían como urgente que el Estado promoviera "una campaña tendiente a favorecer la impresión de libros baratos para que los adolescentes estén en condiciones de adquirirlos a bajo precio" (Torres, 1956: 92).

Las críticas y los empeños contra las historietas, afirma Anne Rubenstein (2004: 295), tuvieron pocos resultados directos; lo que hicieron fue que "el gobierno creara leyes, que no se podían poner en práctica, para regular el contenido de las revistas y creara instancias de censura". Categórica, concluye: "las críticas no dieron ningún resultado".

La razón le asiste si con las críticas se pretendía detener o disminuir la producción, circulación y lectura de este tipo de revistas, o modificar sustantivamente su contenido. Eso no

\footnotetext{
${ }^{23}$ Salvador Hermoso se refería a Wilberto L. Cantón, Francisco César Morales, Atenógenes Pérez y Soto, Ignacio Ramírez López, Salvador Novo, Francisco Cuervo Martínez, Delfina Huerta, Alfredo y Carmen Basurto (Ixba, 2014).

${ }^{24}$ AGN, Fondo Adolfo Ruiz Cortines, caja 0866, expediente 545.2/94.
} 
pasó, cuando menos no por las críticas. Lo que sí ocurrió fue que, ligado a los debates en torno a los libros, a su costo y escasez, se generaron condiciones favorables a la decisión de Adolfo López Mateos de crear y distribuir el libro de texto gratuito:

1) Para académicos, periodistas, estudiantes, escritores, funcionarios y profesores, las historietas eran publicaciones menospreciadas que, por su lenguaje, temática e imágenes, difícilmente se considerarían literatura. "Para las minorías cultas y los amantes de las buenas letras", la lectura de pepines era una transgresión, una especie de "prostitución espiritual de los inocentes. Mejor un pueblo de analfabetos puros que una nación de lectores contaminados" (Aurrecoechea y Bartra, 1993: 13).

2) En estos grupos sociales, la inclinación hacia la lectura de pasquines fue interpretada como resultado del impedimento de acceder a libros de calidad. Tal obstáculo se atribuía a la carestía de los libros, pero también a que los seguidores de las historietas era un público con apenas los rudimentos de la lectura, es decir, mexicanos semialfabetizados (Malvido y Martínez, 1984). En consecuencia, había que buscar estrategias para producir y llevar a los lectores libros baratos y ampliar los servicios educativos.

3) El Estado mexicano, aludían los críticos de las historietas, en cumplimiento de su responsabilidad, debía salvaguardar enérgicamente la educación pública de los embates inmorales de estas publicaciones, velar por el desarrollo integral de los educandos y proteger a la infancia y la juventud de revistas nocivas. "Usted, señor presidente, es el médico que sabrá aplicar el cauterio rápido y eficaz que se requiere", escribió un padre de familia a Adolfo Ruiz Cortines. ${ }^{25}$ No hacerlo, advertían algunos, comprometía el futuro del país.

Lo anterior, en un contexto en el que ocurría (y se impulsaba) un proceso de crecimiento acelerado de los sistemas educativos, guiado por la convicción de que la escuela era "la gran alternativa para la erradicación de la ignorancia, el analfabetismo y, en general, el atraso social" (Martínez, 2003); y que "el nivel educativo de la población era determinante en el desarro"lo económico" (Torres, 2004: 195), la lectura de historietas por millones de mexicanos no sólo resultaba incómoda, sino que se interpretaba como un signo contrario al desarrollo y la modernización. El gobierno mexicano debía actuar, pero no emitiendo más reglamentos, pues éstos ya existían. ¿Podría ser el LTC una forma de contrarrestar las lecturas inconvenientes y acercar otras opciones a sus lectores?

${ }^{25}$ AGN, Fondo Adolfo Ruiz Cortines, caja 879, expediente 704/208. 


\section{Conclusiones}

En este trabajo he argumentado que, para entender el origen del libro de texto gratuito, es necesario remitirse no sólo al estudio del panorama educativo y de las políticas emprendidas al respecto, sino también a la esfera editorial del momento. Esta línea de indagación me ha permitido advertir que, en la década de los cincuenta, el mundo del libro en México enfrentaba problemas que, dadas sus características, podrían organizarse en dos grupos:

1) Falta de desarrollo, tensiones internas y externas, mercado restringido y dependencia de subsidios gubernamentales.

- No lograba siquiera cubrir la mitad del mercado potencial de lectores y usuarios de libros en general y escolares.

- Su oferta estaba concentrada en la capital del país y en las grandes ciudades.

- Las librerías eran escasas, y en las existentes se daba una difusión mínima a obras mexicanas.

- La producción nacional enfrentaba restricciones tecnológicas, materiales y económicas.

- La presencia del libro español era marcada y generaba tensiones en el gremio editorial mexicano.

2) Práctica de lecturas valoradas como inadecuadas y contrarias a los propósitos de la educación pública y de modernidad en el país. Las críticas a estas lecturas provenían de profesores, estudiantes universitarios, autores de libros de texto, escritores y grupos de filiación conservadora y religiosa. La carestía y falta de libros, señalaban los críticos, era una de las causas por las que los miles de mexicanos tendían a estas lecturas "inconvenientes".

En este escenario, la creación del LTC encaja con naturalidad como solución a los problemas anteriores. Sus tirajes millonarios, distribución nacional y producción sostenida, le permiten al gobierno mexicano responder a la demanda de intervenir en la producción de libros que desplacen la lectura de historietas y la presencia de libros escolares no mexicanos. Asimismo, con este material educativo gratuito, que llega a todas las escuelas del país, se abre un espacio para difundir obras de autoría nacional, acordes con los propósitos educativos y el nacionalismo de la época.

Además, la producción y entrega de libros de texto gratuitos, por su magnitud, propósito oficial y recursos económicos invertidos, le confieren al Estado mexicano un rasgo revolucionario, de modernidad, progreso y apego a políticas educativas internas y externas. Los libros, a diferencia de historietas e impresos similares, tienden a valorarse como instrumentos de 
redención de la ignorancia, indicios de cultura y prestigio. Bajo esta lógica, el LTG, en su calidad de material impreso educativo cuya producción estaba en manos de un reconocido escritor, Martín Luis Guzmán, sin duda favorecería la imagen del Estado mexicano convertido ahora en editor y en dador de libros.

Finalmente, y en virtud de las circunstancias del mundo editorial mexicano en los años cincuenta, resulta difícil sostener que la creación del LTC, con sus tirajes millonarios y su distribución nacional, le haya arrebatado el mercado a la industria editorial mexicana. Es posible que haya ocurrido lo contrario. Aunque reconozco, y así lo he documentado en un trabajo previo, que con el libro de texto gratuito algunos autores y editores, especialmente no mexicanos, fueron afectados en sus intereses económicos, también considero que esto ocurrió al inicio de su puesta en marcha.

Conjeturo, reconociendo la falta de estudios al respecto, que la distribución ininterrumpida del LTC incidió, con el tiempo, en la ampliación del mercado de lectores. En 1960, alrededor de 4.6 millones de niños de escuelas primarias recibieron libros de texto gratuitos. Si se toma en cuenta que desde esa fecha la distribución ha sido constante, que los niños recibían cada ciclo escolar un paquete de libros mientras cursaban los seis grados de la educación primaria, que estos materiales debían ser utilizados en clase, que los libros eran bienes que los niños conservaban, y que el LTC, además de ser soporte de los conocimientos prescritos en el plan de estudios, contenía relatos históricos, poesía, fragmentos de cuentos y novelas, biografías, fábulas, descripciones, etc., es posible afirmar que, además de contribuir a la gratuidad y permanencia educativa, el libro de texto gratuitos extendió el mercado de lectores.

Es muy probable que Martín Luis Guzmán y otros editores mexicanos, anticipando esta futura ampliación del mercado mexicano, promovieran y apoyaran decididamente el proyecto del LTG. Hago votos por que en investigaciones venideras se aborden estos y otros temas aledaños.

\section{Fuentes}

Archivos

AGN Archivo General de la Nación, Ciudad de México.

Fondo Presidentes

Fondo Adolfo Ruiz Cortines.

IISUE Instituto de Investigaciones sobre la Universidad y la Educación, UNAM, Ciudad de México.

MLG Fondo Martín Luis Guzmán. 


\section{Bibliohemerografía}

Álvarez de Testa, Lilian (1999), Mexicanidad y libro de texto gratuito, Universidad Nacional Autónoma de México, México.

Aurrecoechea, Juan Manuel y Armando Bartra (1993), Puros cuentos. Historia de la historieta en México 1934-1950, Grijalbo-Conaculta, México.

Ávila, Ana Cristina y Virgilio Muñoz (1999), Creación de la Comisión Nacional de Libros de Texto Gratuitos. La perspectiva escolar 1958-1964, Noriega Editores, México.

Carballo, Emmanuel (2009), "Escritores respaldan vigencia de legado de Alfonso Reyes", El Universal, 26 de noviembre. (2004), Ensayos selectos, Universidad Nacional Autónoma de México, México.

Chine, Dalila (2007), "Los símbolos de la patria mexicana en los libros de texto gratuito", XVI Congreso de la Asociación Internacional de Hispanistas, Centre Malesherbes de la Universidad de París IV, Sorbona, julio de 2007, en <https://cvc.cervantes.es/literatura/aih/pdf/16/aih_16_2_296.pdf> (fecha de consulta: 11/4/2018).

Comisión Nacional de Libros de Texto Gratuitos (Conaliteg) (1994), 35 años de historia, Conaliteg, México. Diario Oficial de la Federación (DOF) (1959), "Decreto que crea la Comisión Nacional de Libros de Texto Gratuitos", DOF, t. CCXXXII, núm. 36, 13 de febrero, Ciudad de México, pp. 4-5.

(1958), "Decreto que establece la Comisión para formular un Plan Nacional destinado a resolver el problema de la educación primaria en el país", DOF, t. CCXXXI, núm. 49, 31 de diciembre, Ciudad de México, pp. 13-14.

(1951), "Reglamento de los artículos 4 y 6, fracción VII, de la Ley Orgánica de la Educación Pública, sobre publicaciones ilustradas en lo tocante a la cultura y a la educación", DOF, t. CLXXXVI, núm. 10, 12 de junio, Ciudad de México, pp. 4-6.

(1944), "Reglamento de revistas ilustradas en lo tocante a la educación", DOF, t. CXLIII, núm. 10, Segunda Secc., 11 de marzo, Ciudad de México, pp. 1-2.

Díaz, Roger (2006), "Los libros escolares mexicanos 1959-2006", en Primer seminario internacional de textos escolares SITE 2006, Santiago de Chile, en <http://www.cerlalc.org/libroaldia/libroaldia_8/ imagenes/noticias/SITE.pdf> (fecha de consulta: 10/10/2010).

Dirección General de Estadística (DCE) (1959), México en cifras 1959, DCE, México.

El Libro y el Pueblo (1954a), t. XVI, núm. 4, abril, Ciudad de México.

(1954), t. XVI, núms. 7-8, julio-agosto, Ciudad de México.

(1955), t. XVII, núm. 15, marzo, Ciudad de México.

Excélsior (1955), 18 de febrero, Ciudad de México.

Fernández, María (2009), "Multinacionales del castellano. El proceso de internacionalización del sector editorial español (1898-2008)", Revista de Historia Industrial, Economía y Empresa, núm. 40, pp. 23-49.

Gallo Martínez, Víctor y Smart de la C. Gómez (1948), La escuela rural mexicana: drama, reto y desafío. Primer Congreso Nacional de Educación Rural, SEP-Sindicato Nacional de Trabajadores de la Educación (SNTE), México.

Greaves, Cecilia (1999), "La Secretaría de Educación Pública y la lectura, 1960-1985", en Seminario de Historia de la Educación en México, Historia de la lectura en México, El Colegio de México, México, pp. 338-372.

(2008), Del radicalismo a la unidad nacional. Una visión de la educación en el México contemporáneo 1940-1964, El Colegio de México, México.

Hernández, Juan (1986), La Comisión Nacional de los Libros de Texto Gratuitos en el sexenio del presidente Adolfo López Mateos 1959-1964, Universidad Michoacana de San Nicolás de Hidalgo, Morelia. 
Hernández, Santiago (1951), Curiosidades y ejemplos. Libro de lectura para cuarto año, Luis Fernández G. Editor, México.

Índice (1953), Índice. Literatura y bibliografía, dir. José María Francés, año IV, núm. 18, $1^{\circ}$ de abril, ed. José C. Torres y Cía., S. de R.L. de C.V., México.

Ixba, Elizer (2014), "El Estado mexicano: ¿artífice del libro de texto gratuito? Origen y hechura de la primera generación de los LTC (1959-1964)", Departamento de Investigaciones Educativas, Centro de Investigación y de Estudios Avanzados (Cinvestav) del IPN, México, tesis de doctorado.

(2013), "La creación del libro de texto gratuito en México (1959) y su impacto en la industria editorial de su tiempo: autores y editoriales de ascendencia española", Revista Mexicana de Investigación Educativa, núm. 59, pp. 1189-1211.

Letras. Publicación literaria y bibliográfica (1956), año XXV, núm. 146, 30 de abril, Librería y Ediciones Botas, S.A., México.

(1955), año XVII, núm. 145, 30 de abril, Librería y Ediciones Botas, S.A., México.

Loaeza, Soledad (1988), Clases medias y política en México. La querella escolar, 1959-1963, El Colegio de México, México.

Loyo, Aurora (2011), "Caminos entreverados: cultura y educación en Jaime Torres Bodet", en Rebeca Barriga Villanueva (ed.), Entre paradojas: a cincuenta años de los libros de texto gratuitos, El Colegio de México-SEP-Conaliteg, México, pp. 121-146.

Malvido, Adriana y Teresa Martínez (1984), "La historieta en México: un mundo ancho y ajeno", Casa del Tiempo, núm. 42: 19-21.

Martínez Boom, Alberto (2003), "De la escuela expansiva a la escuela competitiva en América Latina", Lecciones y Lectura en Educación, núm. 2, pp. 15-44.

Meneses, Ernesto (1988), Tendencias educativas oficiales en México 1934-1961, Centro de Estudios Universitarios-Universidad Iberoamericana, México.

Pérez, Laura (2011), "Censura y control. La Campaña Nacional de Moralización en los años cincuenta", Historia y Grafía, núm. 37, pp. 79-113, en <http://www.redalyc.org/src/inicio/ArtPdfRed. jsp?iCve=58922287004> (fecha de consulta: 5/10/2013).

Rubenstein, Anne (2004), Del Pepín a Los agachados. Cómics y censura en el México posrevolucionario, Fondo de Cultura Económica, México.

Schmelkes, Sylvia (2010), "Torres Bodet, el Plan de Once Años y los libros de texto gratuitos", Instituto de Investigaciones para el Desarrollo de la Educación (Inide)/Universidad Iberoamericana, Ciudad de México, documento pdf disponible en: <https://reposital.cuaed.unam.mx:8443/xmlui/bitstream/ handle/123456789/1899/Mesa\%201l-Schmelkes-presentaci \%C3\%B3n. pdf? sequence=1\&isAllowed=y> (fecha de consulta: 20/03/2018).

Secretaría de Educación Pública (SEP) (1964), La obra educativa en el sexenio 1958-1964, SEP, México. (1956), Memoria 1944-1955, Talleres Gráficos del Departamento de Divulgación de la SEP, México.

Secretaría de Industria y Comercio (1961), Fundamento estadístico del plan de once años de educación primaria, Secretaría de Industria y Comercio, México.

Torres Montalvo, Herculano Ángel (1956), Las tendencias literarias en los adolescentes mexicanos: encuesta realizada entre 1,600 alumnos de escuelas secundarias del Distrito Federal, Secretaría de Educación Pública-Dirección General de Enseñanza Superior e Investigación Científica-Instituto Nacional de Pedagogía, México.

Torres Bodet, Jaime (2005a), "El Plan de Once Años", en Pablo Latapí (comp.), Textos sobre educación, Conaculta, México, pp. 249-260.

(2005b), "Los libros de texto gratuito" en Pablo Latapí Sarre (comp.), Textos sobre educación, Conaculta, México, pp. 261-266. 
Torres Septién, Valentina (2004), La educación privada en México (1903-1976), El Colegio de MéxicoUniversidad Iberoamericana, México.

(2000), Pensamiento educativo de Jaime Torres Bodet, Secretaría de Educación Pública-El Caba\|lito, México.

(1999), "La lectura, 1940-1960", en Seminario de Historia de la Educación en México, Historia de la lectura en México, El Colegio de México, México, pp. 338-372.

Últimas Noticias (1955), 19 de marzo, Ciudad de México.

Vázquez, Josefina Zoraida (2000), Nacionalismo y educación en México, El Colegio de México, México.

Villa Lever, Lorenza (2009), Cincuenta años de la Comisión Nacional de Libros de Texto Gratuitos: cambios y permanencias en la educación mexicana, Conaliteg, México.

Weiss, Eduardo (1982), "Los valores nacionales en los libros de texto de ciencias sociales: 1930, 1980", Educación. Revista del Consejo Nacional Técnico de Educación, núm. 42, pp. 321-341.

Zahar, Juana (2000), Historia de las librerías de la ciudad de México: evocación y presencia, Centro Universitario de Investigaciones Bibliotecológicas (CUIB)/UNAM-Plaza y Valdés, México.

Elizer IXba Alejos es Doctora en Ciencias, con especialidad en Investigaciones Educativas por el Centro de Investigación y de Estudios Avanzados (Cinvestav) del Instituto Politécnico Nacional (IPN). Es profesora-investigadora de la Universidad Autónoma de la Ciudad de México, Colegio de Humanidades y Ciencias Sociales. Sus líneas de investigación son la historia del libro de texto gratuito en México, historia de la cultura escrita e historia de la educación básica en México. Es autora de "Jóvenes y estudiantes: tres formas de ser universitario y de apropiarse de la universidad", en Norma A. Gómez y María E. Pedraza (coords.), Género, relaciones de pareja y violencia en contextos universitarios. Análisis de la Universidad Autónoma de la Ciudad de México, (Ítaca, México, 2015, pp. 51-74); "La creación del libro de texto gratuito en México (1959) y su impacto en la industria editorial de su tiempo: autores y editoriales de ascendencia española", Revista Mexicana de Investigación Educativa, vol. 18 (59) (2013): 1189-1211, y (en coautoría con Susana Quintanilla), "Martín Luis Guzmán y los primeros libros de texto gratuitos en México", en La educación pública: patrimonio social de México, vol. 2, Temas de nuestro tiempo (México: FCE, 2011), pp. 143-167.

Recibido: 16 de marzo de 2016

Aceptado: 13 de abril de 2018 